\title{
Removal of oxyfluorfen from soil washing fluids using electrolysis with diamond anodes
}

\author{
Elisama Vieira dos $\operatorname{Santos}^{1}$, Cristina Sáez ${ }^{2}$, Carlos Alberto Martínez-Huitle ${ }^{1, *}$, \\ Pablo Cañizares ${ }^{2}$, Manuel Andres Rodrigo ${ }^{2}$ \\ ${ }^{1}$ Institute of Chemistry, Federal University of Rio Grande do Norte, Lagoa Nova CEP 59078-970, \\ Natal, RN, Brazil \\ ${ }^{2}$ Department of Chemical Engineering, Universidad de Castilla - La Mancha, Enrique Costa \\ Building. Campus Universitario s/n. 13071 Ciudad Real. Spain
}

\begin{abstract}
In this work, it is studied the treatment of soil spiked with oxyfluorfen by a surfactant-aided soilwashing (SASW) process followed by the electrolytic treatment with boron doped diamond (BDD) anodes of the resulting soil washing liquid. Results demonstrate that SASW is very efficient in the treatment of the soil and it attains the total removal of the pesticide with dosages below $5 \mathrm{~g}$ of sodium dodecyl sulphate (SDS)/Kg of soil. Main characteristics of the effluents produced in this soil remediation technology depend on the dosage and so does the efficiency of their electrolytic treatment with diamond anodes. Electrolysis demonstrates to be a very efficient technology for the removal of oxyfluorfen from the washing fluid and it attains the complete mineralization for the five effluents studied, regardless of the very different initial speciation (in special in terms of the size of the particles). Electrolysis of soil washing fluids proceeds though the reduction in size of micelles till their complete depletion. Very low concentration of intermediates is produced and role of sulfate (coming from SDS) and chlorine (coming from oxyfluorfen) was important.
\end{abstract}




\section{Keywords}

Oxyfluorfen, electrolysis, soil remediation, soil washing, boron doped diamond.

\section{Highlights}

- SASW with SDS surfactant is an efficient technology for removing oxyfluofen from spiked clay soils.

- BDD anodic oxidation is very efficient for the treatment of SASW effluents containing oxyfluorfen

- Electrolysis of soil washing fluids proceed though the reduction in size of micelles.

- Key role is played by sulfate and chlorine released from SDS and oxyfluorfen. 


\section{Introduction}

Oxyfluorfen is a diphenyl-ether herbicide used for broad spectrum pre- and post-emergent control of annual broadleaf and grassy weeds in a variety of tree fruit, nut, vine, and field crops. The largest agricultural markets are wine grapes and almonds. There are also non-agricultural ornamental and forestry uses. Oxyfluorfen is also used for weed control in landscapes, patios, driveways, and similar areas in residential sites. The compound (Figure 1) has low water solubility $\left(0.116 \mathrm{mg} \mathrm{dm}^{-3}\right.$ at $\left.20{ }^{\circ} \mathrm{C}\right)$, low vapour pressure $\left(0.026 \mathrm{mPa}\right.$ at $\left.25^{\circ} \mathrm{C}\right)$, high $\mathrm{K}_{\mathrm{oc}}(\log \mathrm{Koc}=3.46-4.13)$ and high $\mathrm{K}_{\mathrm{ow}}(\log$ Kow $=4.86)[1]$.

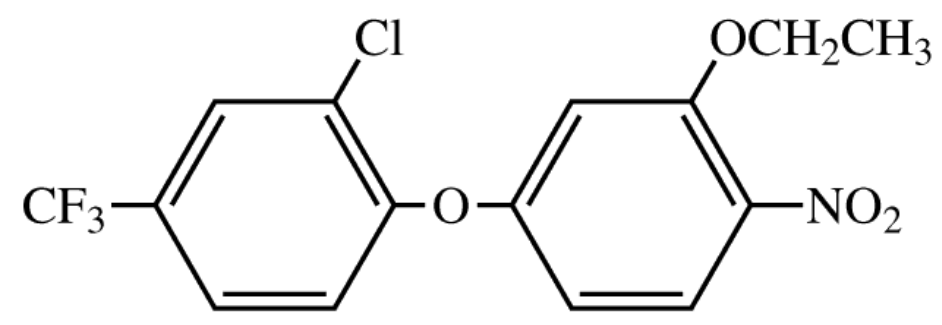

Fig. 1. Oxyfluorfen molecule

Oxyfluorfen has the potential to affect terrestrial plants and aquatic ecological systems at all levels, as it is toxic to plants, invertebrates, and fish, and it has been shown to drift from application sites to nearby areas. As a consequence, birds and mammals may also experience subchronic and chronic effects from oxyfluorfen use [2-5]. For this reason, it is very important the rapid actuation against accidental discharges of hazardous species with efficient technologies that remediate the soil rapidly and avoids diffuse pollution. One of these technologies is Surfactant-Aided Soil Washing (SASW), successfully studied for the remediation of soils polluted with pesticides and polycyclic aromatic hydrocarbons (PAHs) [6-9]. This approach involves washing the soils with an aqueous 
surfactant solution, with the aim of enhancing the water solubility of the organic compounds by forming oil/water (O/W) emulsions with micro-drops of pollutant compounds [9].

However, this type of effluent is difficult to be treated by conventional wastewater treatment methods due to the refractory properties of the organic compounds and surfactants [9]. For this reason, many works have focused on developing efficient technologies to treat these effluents and these include advanced oxidation processes (AOPs), such as electrochemical oxidation (EO) [1014], photodegradation [15-17] and electro-fenton [18-20].

At present, one of the most relevant technologies for the treatment of $\mathrm{O} / \mathrm{W}$ emulsions is the electrolysis with diamond electrodes, which has become a reference in the recent years for the depletion of persistent organic pollutant contained in wastewater [21-26]. In fact, this type of electrolysis has received a great deal of attention, thanks to the attractive characteristics of diamond anodes, such as versatility, energy efficiency, amenability of automation, and environmental compatibility (free chemical reagents). Its high efficiency is associated to the production of many types of oxidant species, ranging from hydroxyl radicals $(\bullet \mathrm{OH})$ formed by water electrolysis [27] to $\mathrm{S}_{2} \mathrm{O}_{8}{ }^{2-}, \mathrm{Cl}_{2}, \mathrm{ClO}_{2}{ }^{-}$or $\mathrm{C}_{2} \mathrm{O}_{6}{ }^{2-}$ produced from the electrolyte salts [28-34]. Treatment with this technology of complex wastewater, such as soil washing fluids polluted with pesticides, is a topic of a great interest nowadays, because it involves the study of the removal of highly toxic microemulsions [6]. Due to heterogeneity, treatment of emulsions becomes a handicap, as compared to the typical studies focused on the treatment of wastewater polluted with soluble organics. Taking into account this background, the objective of this study was to investigate under laboratory conditions the remediation of soils polluted with oxyfluorfen by a combined treatment consisting of the soil washing with a SDS solution followed by the electrolysis with BDD anodes of the washing fluid obtained in the SASW process. Effect of the ratio surfactant/soil is going to be assessed trying to determine is influence in the soil washing efficiency and in the characteristics of the washing waste. 


\section{Materials and methods}

Reagents. Oxyfluorfen (2-chloro-1-(3-ethoxy-4-nitrophenony)-4-(trifluoromethyl), 99.8\% purity benzene, HPLC-grade acetonitrile, ethyl acetate and hexane were obtained from Sigma-Aldrich (Spain). Sodium dodecyl sulphate (SDS) used as solubilizing agent and sodium hydrogen carbonate $\left(\mathrm{NaHCO}_{3}\right)$ were obtained from Panreac. Deionized water (Millipore Milli-Q system) was used to prepare all solutions.

Analytic techniques. The oxyfluorfen concentration in the liquid phase was determined using a liquid-liquid $(\mathrm{L}-\mathrm{L})$ extraction process. This process was carried out in separator flasks of $100 \mathrm{~cm}^{3}$ using ethyl acetate/hexane as extraction solvent (ratio oxyfluorfen solution/solvent $=0.52 \mathrm{v} / \mathrm{v}$ ). All samples extracted from electrolyzed solution were filtered with $0.25 \mu \mathrm{m}$ nylon Whatman filters before analysis. The concentrations of the compounds were quantified by HPLC (Agilent 1100 series) using analytical column Phenomenex Gemini $5 \mu \mathrm{m} \mathrm{C18.} \mathrm{The} \mathrm{detection} \mathrm{wavelength} \mathrm{of} 220$ nm was used and the temperature oven was maintained at $25^{\circ} \mathrm{C} .20 \mu \mathrm{L}$ aliquots were injected, using as mobile phase, a mixture of acetonitrile/water $(70: 30(\mathrm{v} / \mathrm{v}))$ at $0.3 \mathrm{~cm}^{3} \mathrm{~min}^{-1}$. The total organic carbon (TOC) concentration was monitored using a Multi N/C 3100 Analytik Jena analyser. The oxyfluorfen and surfactant removal were monitored through the COD content during electrolysis using a HACH DR2000 analyser. Zeta potential was also measured for the clarified liquid using a Zetasizer Nano ZS (Malvern, UK). Measurements of pH were carried out with an InoLab WTW pH-meter. The particle size was monitored during EO with a Mastersizerhydro 2000SM (Malvern). The colorimetric method used to determine the concentration of the SDS surfactant has been reported by Jurado et al. [35]. The anions present in the target wastewater were characterized using ion chromatography by means of a Shimadzu LC-20A system [36]. 
Preparation of spiked soil. The procedure used to pollute the soil consisted on solubilisation of oxyfluorfen in acetonitrile and mixing this oxyfluorfen/acetonitrile solution with kaolinite. The spiked clay was aerated for 1 day to favour evaporation of the acetonitrile. In this way, the oxyfluorfen was homogeneously distributed on the clay surface. The concentration of oxyfluorfen present in the soil at the beginning of the experiments was fixed at $100 \mathrm{mg} / \mathrm{kg}$.

Soil washing procedure. Soil washing with surfactant fluid solution was carried out in a stirred tank operated in discontinuous mode. The tank volume was $1000 \mathrm{~cm}^{3}$. Low-permeability soil (1000 g) polluted with $100 \mathrm{mg}$ oxyfluorfen $\mathrm{kg}^{-1}$ of soil and $800 \mathrm{~cm}^{3}$ of solubilizing agent (containing deionized water, $500 \mathrm{mg} \mathrm{dm}^{-3}$ of $\mathrm{NaHCO}_{3}$, and different concentrations of SDS surfactant ranging from 100 to $5000 \mathrm{mg} \mathrm{dm}^{-3}$ were mixed in the reactor for $6 \mathrm{~h}$ at a stirring rate of $120 \mathrm{rpm}$. The same tank then acted as a settler (during $24 \mathrm{~h}$ ) to separate the soil from the effluent. These effluents consisted of complex aqueous mixtures of oxyfluorfen, surfactant and sodium hydrogen carbonate, with emulsified micro drops and soluble species, which become the influent of the electrolytic treatment.

Electrochemical oxidation of the soil washing effluents. EO experiments were carried out in a bench-scale plant with a single-compartment electrochemical flow cell. Bulk oxidations were performed in a single-compartment cell, as described in previous works $[6,8]$. BDD and steel electrodes were used as anode and cathode, respectively. Characteristic of BDD are as follows: $\mathrm{sp}^{3} / \mathrm{sp}^{2}$ ratio of 225 ; boron content about $500 \mathrm{ppm}$ and width of the diamond layer of $2.68 \mu \mathrm{m}$. For the electrochemical flow cell, inlet and outlet were provided for effluent circulation through the reactor; the SASW effluent was stored in a thermo-regulated glass tank $\left(1000 \mathrm{~cm}^{3}\right)$ and circulated through the cell using a peristaltic pump at a flow rate of $200 \mathrm{dm}^{3} \mathrm{~h}^{-1}$. The electrical current was applied using a DC Power Supply (FA-376 PROMAX). Temperature was kept constant by means of a water bath. 


\section{Results and Discussions}

SASW process. One of the key points in the remediation of soil polluted with pesticide is to transfer the pesticide from the soil matrix into a simpler and easier to be treated liquid phase. Thus, difficulties associated to the treatment in a heterogeneous media are minimized. For pesticides with a low solubility, the washing fluid dosed should contain surfactants, being SDS one of the most commonly used, because of the typically high efficiencies attained and its low hazardousness [7, 8 , 37, 38]. Then, samples of the polluted soil $(0.2 \mathrm{Kg})$ were treated by SASW process using different SDS concentrations (from 100 to $5000 \mathrm{mg} \mathrm{L}^{-1}$ ). After that, the remaining concentrations of oxyfluorfen and SDS were determined in order to establish the decontamination level by SASW process. Figure 2 shows the oxyfluorfen and SDS concentrations in the soil, after a soil washing treatment of the spiked soil studied, as a function of SDS/soil ratio. As expected, the higher the amount of SDS used, the lower the oxyfluorfen and the higher is the SDS remaining concentrations in the soil. For SDS/soil ratios above $5 \mathrm{~g} \mathrm{Kg}^{-1}$, surplus oxyfluorfen is negligible in the soil and under the detection limits of the HPLC $\left(0.25 \mathrm{mg} \mathrm{dm}^{-3}\right)$. This means that from a practical point of view, higher doses are not useful neither cost-effective, because they only lead to increase unnecessarily the surfactant content of the soil.

In comparing the resulting washing fluids, it can be observed that the mean size of the micelles depends on the ratio SDS/soil applied in the soil washing process, see Fig. 2. The higher the amount of SDS, the lower is the mean micelle size and the more negative is the resulting particle (according to the z-potential measurement). Size of micelles tends to a constant value for high values of the SDS/soil ratio (Fig. 2). In contrast, charge is not stabilized but it continues decreasing for higher doses. All these results indicate that the resulting washing fluids characteristics depend strongly on the dose of surfactant, and it could be a determining parameter for the successive electrochemical treatment. 
In comparing these results with previous studies of this group made with atrazine [6], many similarities can be found, such as lower size of micelles and more negative charge with increasing SDS/soil ratio. It can be also stated that main changes observed during the SASW process are the total depletion of pesticide attained (in the case of atrazine [6], surplus concentration was about 1 $\mathrm{mg} \mathrm{Kg} \mathrm{Kg}^{-1}$ at very large SDS dosages) and the differences in the main characteristics of the washing fluid since the mean size and total charge with seems to depend on the nature of the pesticide washed from soil. Thus, for the largest SDS/soil ratio dosed $\left(25 \mathrm{~g} / \mathrm{kg}^{-1}\right)$, the washing fluid for atrazine leads to an average micelles size of $178.22 \mu \mathrm{m}$ and a charge of $-51 \mathrm{mV}$, while for oxyfluorfen, for the same ratio average micelles size was $28.3 \mu \mathrm{m}$ and the charge was $-65.4 \mathrm{mV}$.
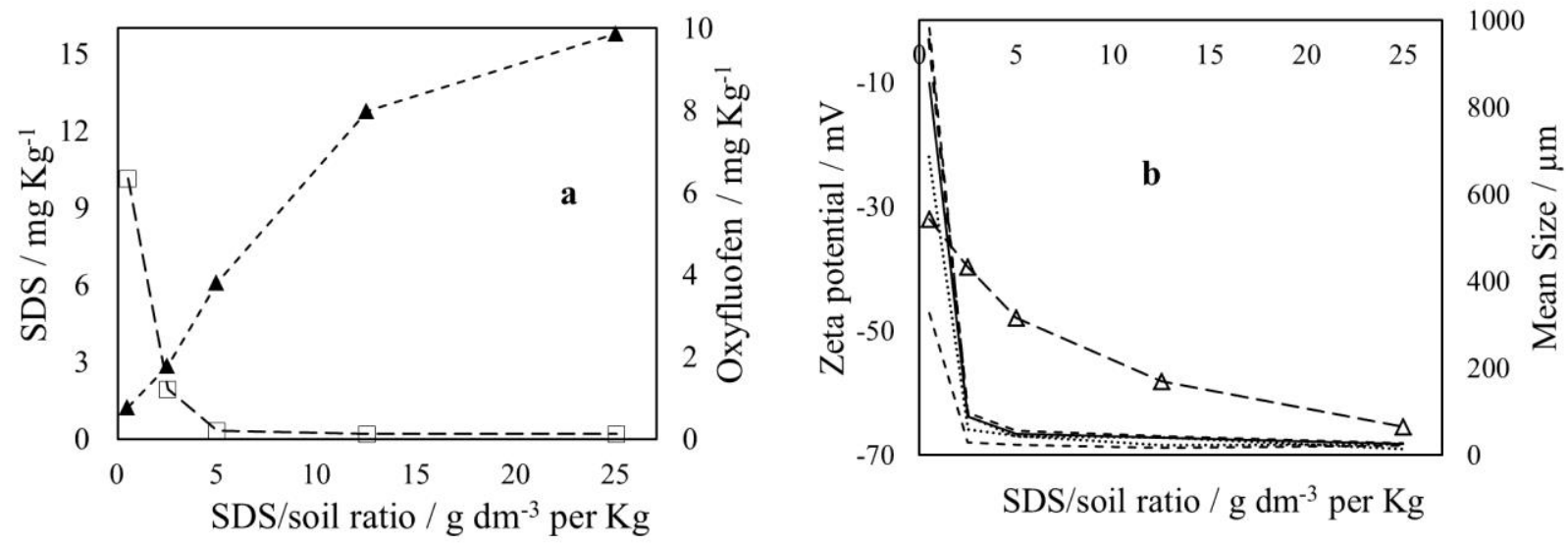

Fig. 2. Evaluation of soil polluted with oxyfluofen after washing process with different SDS concentrations, as a function of SDS/soil ratio: (a) ( $\boldsymbol{\Delta})$ Remaining SDS and ( $\square$ ) oxyfluorfen concentrations in the soil; (b) $(\Delta)$ Zeta potential and size limits including ( - - - ) $50 \%$ of the particles; size limits including $80 \%$ of the particles ( $\ldots . .$.$) .$

Obviously, in spite of having the same two species (the oxyfluorfen pesticide and the SDS surfactant), the washing fluids are completely different wastes, and these should behave in a diverse way when undergo EO with conductive diamond electrodes. 


\section{Electrolysis of soil washing effluents}

Bulk electrolysis were performed with different effluents generated $\left(0.7 \mathrm{dm}^{3}\right)$ by SASW process applying $300 \mathrm{~A} \mathrm{~m}^{-2}$. Figure 3 compares the changes in the size and charge of particles during these electrolysis tests. As it can be observed, during the electrochemical treatment, mean size of micelles decreases rapidly and after $10 \mathrm{Ah} \mathrm{m}^{-3}$, these are below the detection limit of the particle size analyzer. Decrease size particle rate seems to follow an exponential decay and except for the washing fluid obtained at the lowest SDS/soil ratio (0.5 mg SDS Kg-1 of soil). Likewise, it is important to point out the time course of the micelles charged because they do not follow the same trend (decreasing or increasing) but these tend to an intermediate z-potential value of about $-50 \mathrm{mV}$. This kind of variation was also observed in our previous work about the treatment of atrazine soil washing fluids [6], but in this case the final z-potential was slightly lower $(-35 \mathrm{mV})$. In this frame, we can infer that this value should be related to the structure of the smallest micro-drops produced in the waste during the electrochemical treatment. Hence, the lower polarity of the oxyfluorfen (when compared to atrazine) indicates the higher amount of SDS required to stabilize a constant emulsified microdrop.
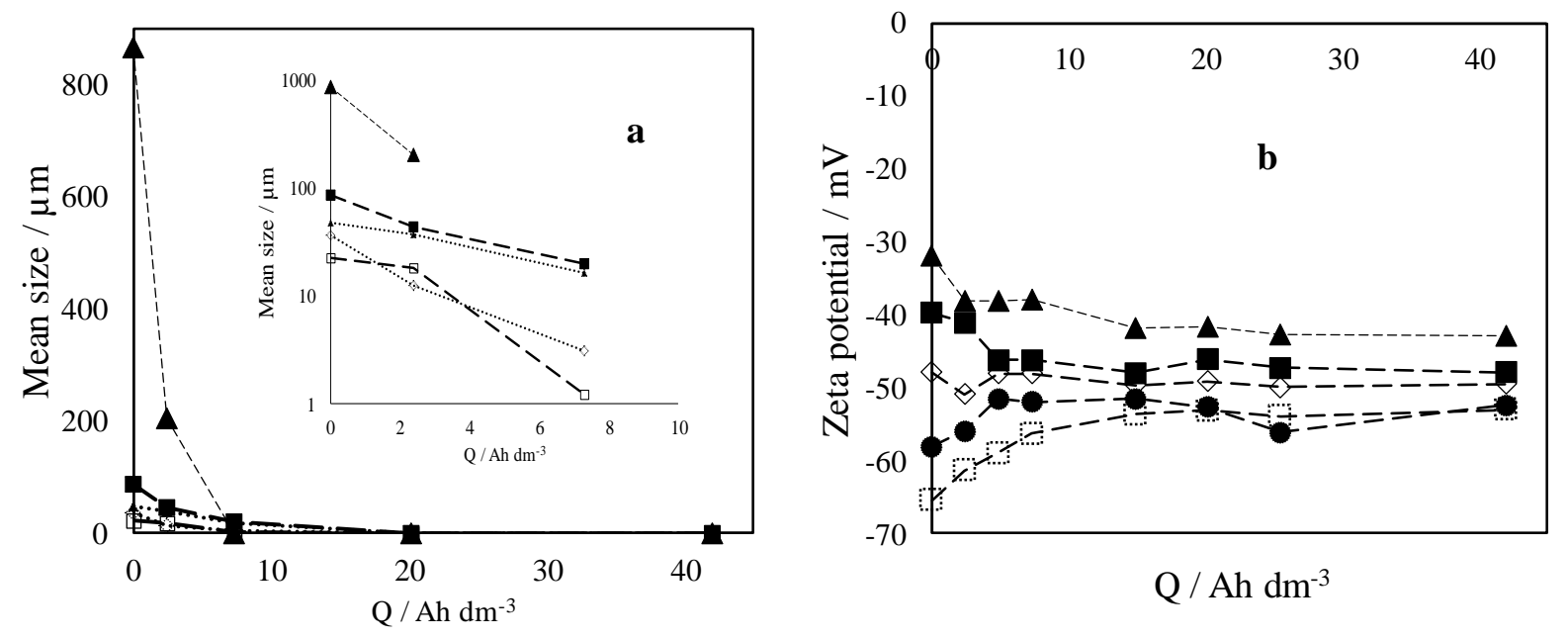
Fig. 3. Changes in the particle size (a) and z-potential (b), as a function of electrical charge passed (Q), during the electrolysis with diamond electrode (constant $j=300 \mathrm{~A} \mathrm{~m}^{-2}$ ) of soil-washing effluents obtained with different SDS/soil dosages: $(\boldsymbol{\Delta}) 0.5 \mathrm{~g} \mathrm{~kg}^{-1},(\boldsymbol{\bullet}) 2.5 \mathrm{~g} \mathrm{~kg}^{-1},(\diamond) 5.0 \mathrm{~g} \mathrm{~kg}^{-1},(\bullet)$ $12.5 \mathrm{~g} \mathrm{~kg}^{-1}$ and (口) $25 \mathrm{~g} \mathrm{~kg}^{-1}$.

Changes in the average size of the particles reflect on the value of the turbidity, as it is shown in Figure 4. This parameter decreases with the electrical charge passed (Q) during the electrolysis time. In comparing the initial values, it can be stated that it has a clear trend, completely opposite to that discussed for the size of the particles. Higher turbidities are obtained for the washing fluids with higher SDS/soil ratios because in these soils the ratio of small particles is much higher as compared to the washing fluids with lower SDS/soil ratio and it is important to bear in mind that turbidity is a measurement related to the colloids contained in the fluid.

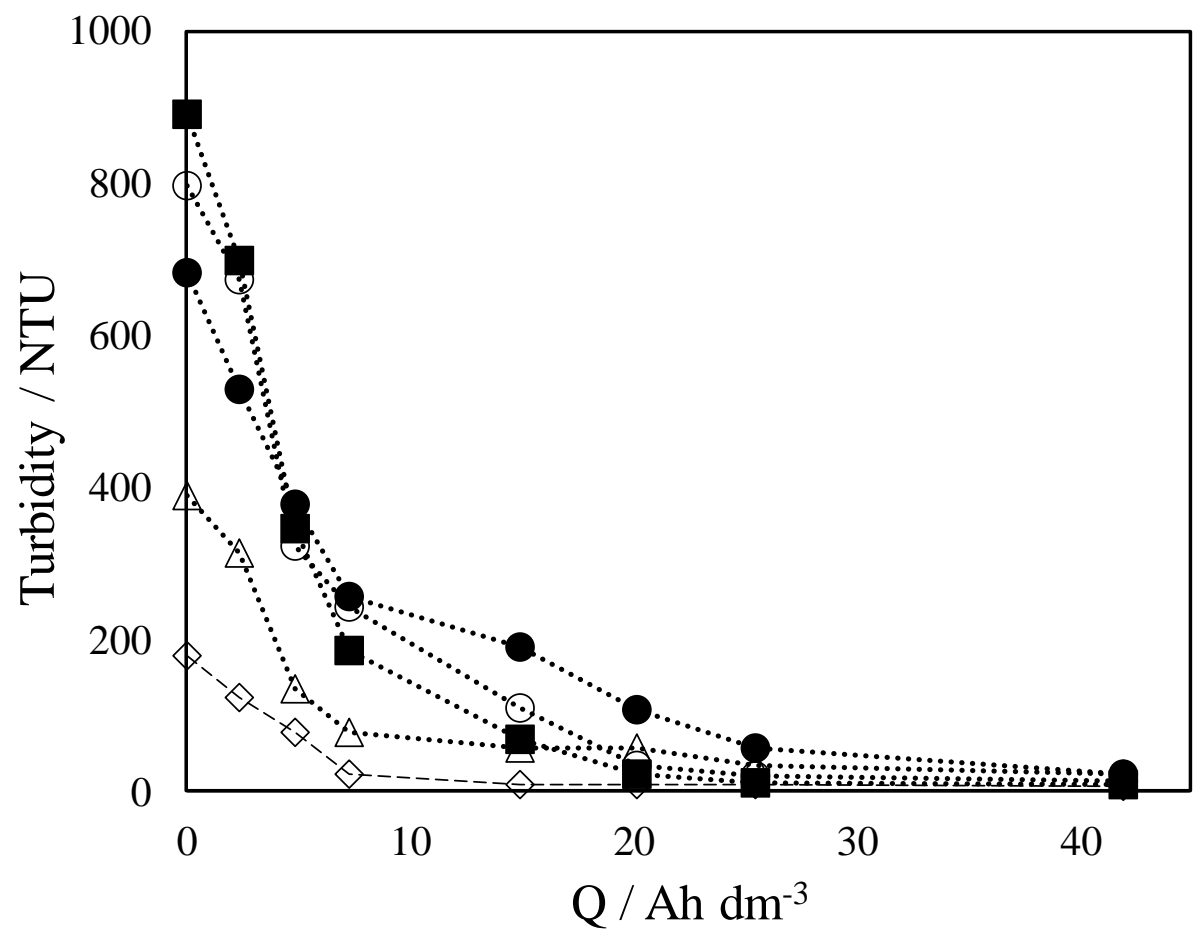

Fig. 4. Changes in the turbidity during the electrolytic treatment (constant j $300 \mathrm{~A} \mathrm{~m}^{-2}$ ) of SASW effluents obtained during the soil washing with different SDS/soil dosages, as a function of 
electrical charge passed $(\mathrm{Q}):(\diamond) 0.5 \mathrm{~g} \mathrm{~kg}^{-1},(\Delta) 2.5 \mathrm{~g} \mathrm{~kg}^{-1},(\bullet) 5.0 \mathrm{~g} \mathrm{~kg}^{-1},(\odot) 12.5 \mathrm{~g} \mathrm{~kg}^{-1}$ and (匹) 25.0 $\mathrm{g} \mathrm{kg}^{-1}$

Anyhow, a very important point is that turbidity is not increased during the treatment as a consequence of the depletion of large drops (which according to Figure 1 are depleted at $10 \mathrm{kAh} \mathrm{m}^{-}$ ${ }^{3}$ ). Opposite, it keeps in an almost constant value (plateau zone) from 10-20 $\mathrm{kAh} \mathrm{m}^{-3}$ and this fact can be indicative of the oxidation of the microscopic drops (those quantified by turbidity) during the treatment.

The two main species contained in the raw washing fluid were monitored during the tests and results are shown in Figure 5. Taking into account the large differences, results are plotted in semi logarithmic scale. As it can be observed, the SDS surfactant is depleted much faster than oxyfluorfen pesticide, especially when effluents with lower SDS were treated $\left(0.5\right.$ and $\left.2.5 \mathrm{~g} \mathrm{~kg}^{-1}\right)$. This clearly indicates that micelles are attacked on their surface layer by mediated oxidants (hydroxyl radicals) produced during electrolysis. As it is well-know, hydroxyl radicals are produced at BDD surface from electrolysis of water:

$\mathrm{BDD}+\mathrm{H}_{2} \mathrm{O} \rightarrow \mathrm{BDD}(\cdot \mathrm{OH})+\mathrm{H}^{+}+\mathrm{e}^{-}$

After that, as already commented, hydroxyl radicals participate in the fragmentation of micelles in solution:

$\mathrm{BDD}(\mathrm{OH} \bullet)+$ micelles $\rightarrow \mathrm{BDD}+m \mathrm{CO}_{2}+n \mathrm{H}_{2} \mathrm{O}$

Additionally, as can be observed in Fig. 5, the rate of the depletion of SDS is almost constant (same slope in the semi-logarithmic plot) while the rate in the depletion of oxyfluorfen increase with the amount of SDS contained in the washing fluid. 

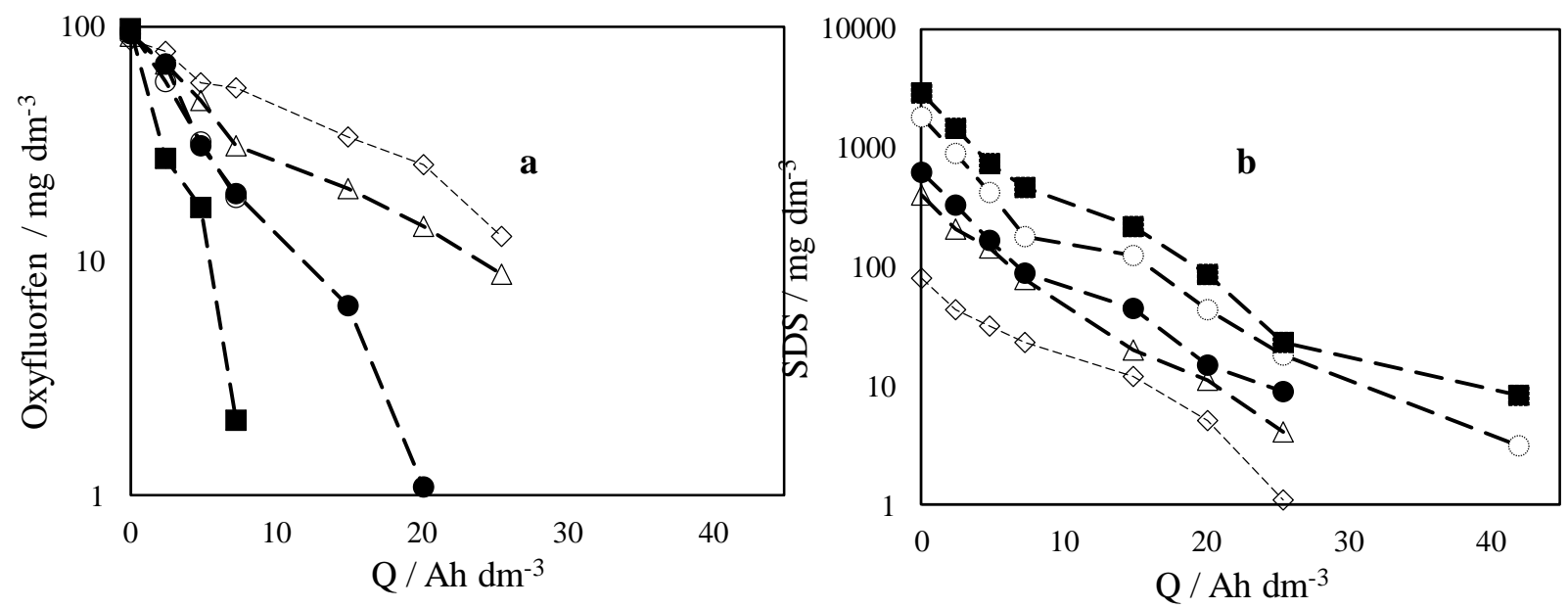

Fig. 5. Changes in the concentration of (a) oxyfluorfen and (b) SDS profiles during the electrolytic treatment $\left(\mathrm{j}=300 \mathrm{~A} \mathrm{~m}^{-2}\right)$ of SASW effluents obtained during the soil washing with different SDS/soil dosages. $(\diamond) 0.5 \mathrm{~g} \mathrm{~kg}^{-1},(\Delta) 2.5 \mathrm{~g} \mathrm{~kg}^{-1},(\bullet) 5.0 \mathrm{~g} \mathrm{~kg}^{-1},(\circ) 12.5 \mathrm{~g} \mathrm{~kg}^{-1}$ and (匹) $25.0 \mathrm{~g} \mathrm{~kg}^{-1}$

At this point, it is worth to take in mind that the oxidation of SDS lead to the production of sulfate $[24,39]$, as it is shown in Figure 6. Total concentration of sulfate released is not directly related to the concentration of SDS added to the soil but to that contained in the washing fluid (according to Figure 2 retention of SDS in the soil increases for large dosages of this surfactant). Anyhow, the higher the dosed used in the soil washing process, the higher is the resulting sulfate released. As it is well studied in the literature, sulfate ions can be further oxidized to peroxosulfate during electrolysis $[25,40]$ :

$2 \mathrm{SO}_{4}^{2-} \rightarrow \mathrm{S}_{2} \mathrm{O}_{8}{ }^{2-}+2 \mathrm{e}^{-}$

Then, mediated oxidation process by hydroxyl radicals and persulfate is the responsible to eliminate the organic matter in solution. This fact can explain the more efficient degradation of oxyfluorfen in the washing fluids which reflects on a higher slope (kinetic constant). Likewise the smaller size of the particles in the highly surfactant loaded washing fluid may promote the faster release of sulfate (Fig. 6), producing persulfate and consequently, attacking to the pesticide. 


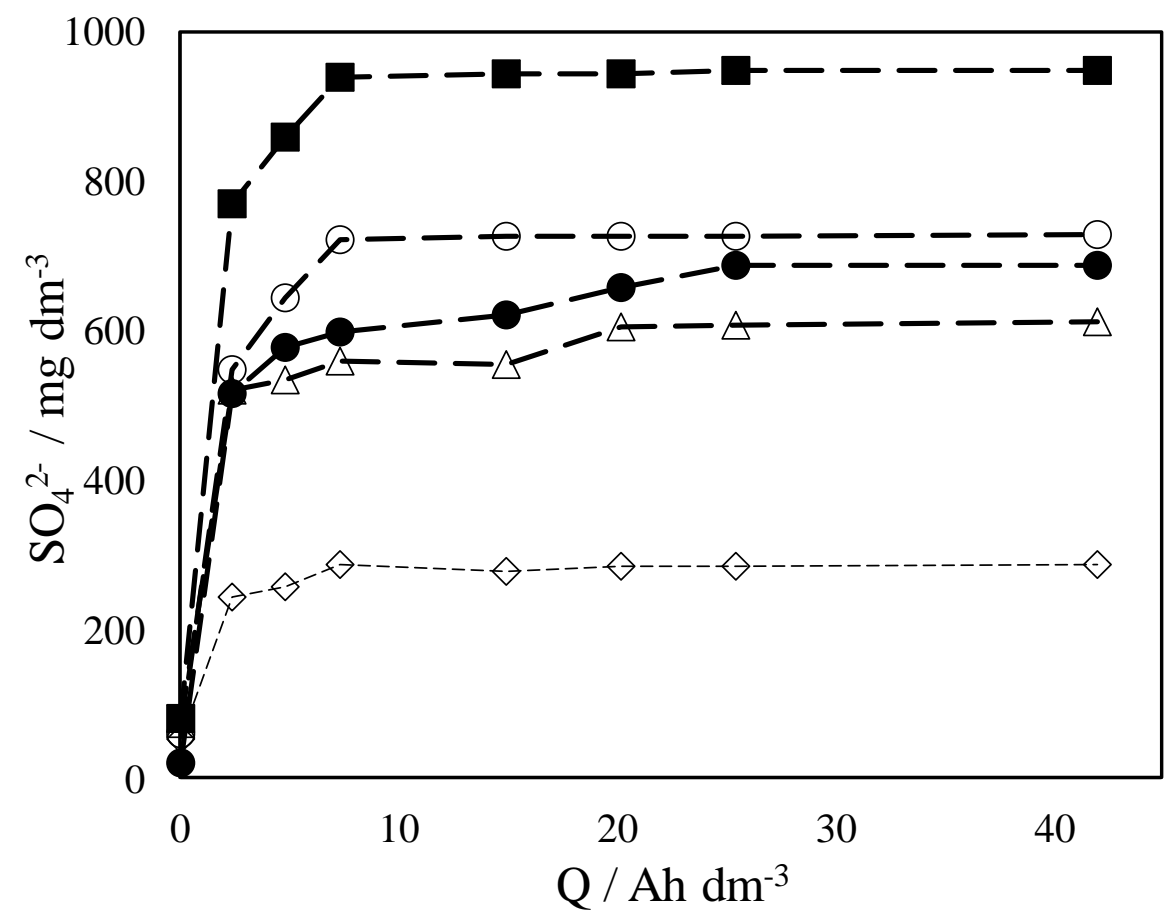

Fig. 6. Sulphate ions produced during the electrolysis $\left(\mathrm{j}=300 \mathrm{~A} \mathrm{~m}^{-2}\right)$ of SASW effluents obtained during the soil washing with different SDS/soil dosages. ( $\diamond) 0.5 \mathrm{~g} \mathrm{~kg}^{-1},(\Delta) 2.5 \mathrm{~g} \mathrm{~kg}^{-1},(\bullet) 5.0 \mathrm{~g} \mathrm{~kg}^{-1}$, (०) $12.5 \mathrm{~g} \mathrm{~kg}^{-1}$ and (ם) $25.0 \mathrm{~g} \mathrm{~kg}^{-1}$.

Obviously, the oxidation of the washing fluid leads to the formation of intermediates. Table 1 reports the total of chromatographic area (related to the concentration) of intermediates detected in each experiment and Figure 7 the TOC and COD which totalized the removal of pollutants in a single parameter. There are only two intermediates which can be followed by HPLC (obtained at 3.7 and 9.0 minutes) and the total chromatographic areas are very low and not depending on the total TOC or COD. This indicates that these intermediates should be related to the oxyfluorfen (whose concentration is almost kept constant in the five raw washing fluids) and not to SDS (whose concentration depends on the ratio SDS/soil used in the soil washing). By comparing with standards [1-4], 4-(trifluoromethyl)-phenol and ortho-nitrophenol were proposed as intermediates. No intermediates coming from SDS are detected. This indicates that intermediates formed during the 
process are very rapidly oxidized and that the most important processes should be occurring on the surface of the micelles.

Table 1. Maximum concentration of intermediates (expressed as chromatographic area) measured during the electrolysis of the soil washing effluents.

\begin{tabular}{|c|c|c|}
\hline SDS/soil $\left(\mathrm{g} \mathrm{L}^{-1}\right.$ per Kg) & Intermediate 1 & Intermediate 2 \\
\hline 0.5 & 1203 & 539 \\
\hline 2.5 & 832 & 645 \\
\hline 5 & 735 & 1565 \\
\hline 12.5 & 913 & 365 \\
\hline 25 & 1023 & 534 \\
\hline
\end{tabular}

On the other hand, in comparing the TOC and COD changes, higher values of both parameters obtained with increasing SDS/soil ratio in the soil washing are easily explained in terms of the higher initial concentration of surfactant. Anyhow, as the process efficiently clearly depends on the concentration (mass transport controlled process), the total electric charge required for the complete mineralization is nearly the same for the five washing fluids tested (around $25 \mathrm{Ah} \mathrm{m}^{-3}$ ).
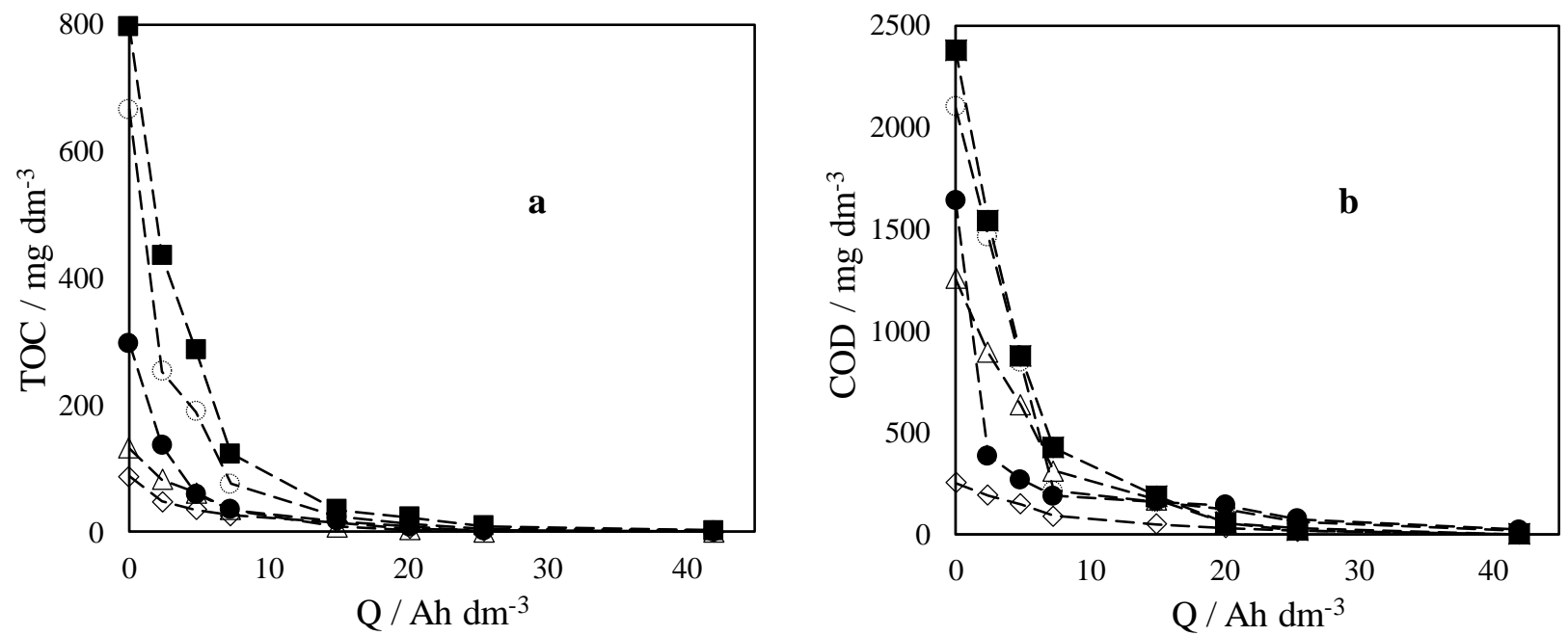
Fig. 7. Changes in the TOC and COD during the electrolytic treatment $\left(j=300 \mathrm{~A} \mathrm{~m}^{-2}\right)$ of SASW effluents obtained during the soil washing with different SDS/soil dosages. $(\diamond) 0.5 \mathrm{~g} \mathrm{~kg}^{-1},(\Delta) 2.5 \mathrm{~g}$ $\mathrm{kg}^{-1},(\bullet) 5.0 \mathrm{~g} \mathrm{~kg}^{-1},(\circ) 12.5 \mathrm{~g} \mathrm{~kg}^{-1}$ and ($) 25.0 \mathrm{~g} \mathrm{~kg}^{-1}$

Finally the release of chlorine during oxidation of the oxyfluorfen is also an important point. Chlorine is contained in the chemical structure of the pesticide, as can be observed in Figure 1, and it is mainly transformed into hypochlorite during electrolysis (Fig. 8). This observation was not expected because typically the final product in the oxidation with diamond electrodes of chloride is not chlorine/hypochlorite but perchlorates, in particular at the range of current densities applied [4144]. However, during the treatment of the five washing fluids studied, occurrence of chlorates and perchlorates was very low and they do not behave as final products but as intermediates. Another remarkable point is that final concentration of chlorinated species in the liquid is not the same; in spite all the washing fluids had almost the same initial concentration of oxyfluorfen. Stripping of gaseous chlorine and the complex chemistry of persulfates and oxidized chlorine species can help to understand this anomalous behavior.
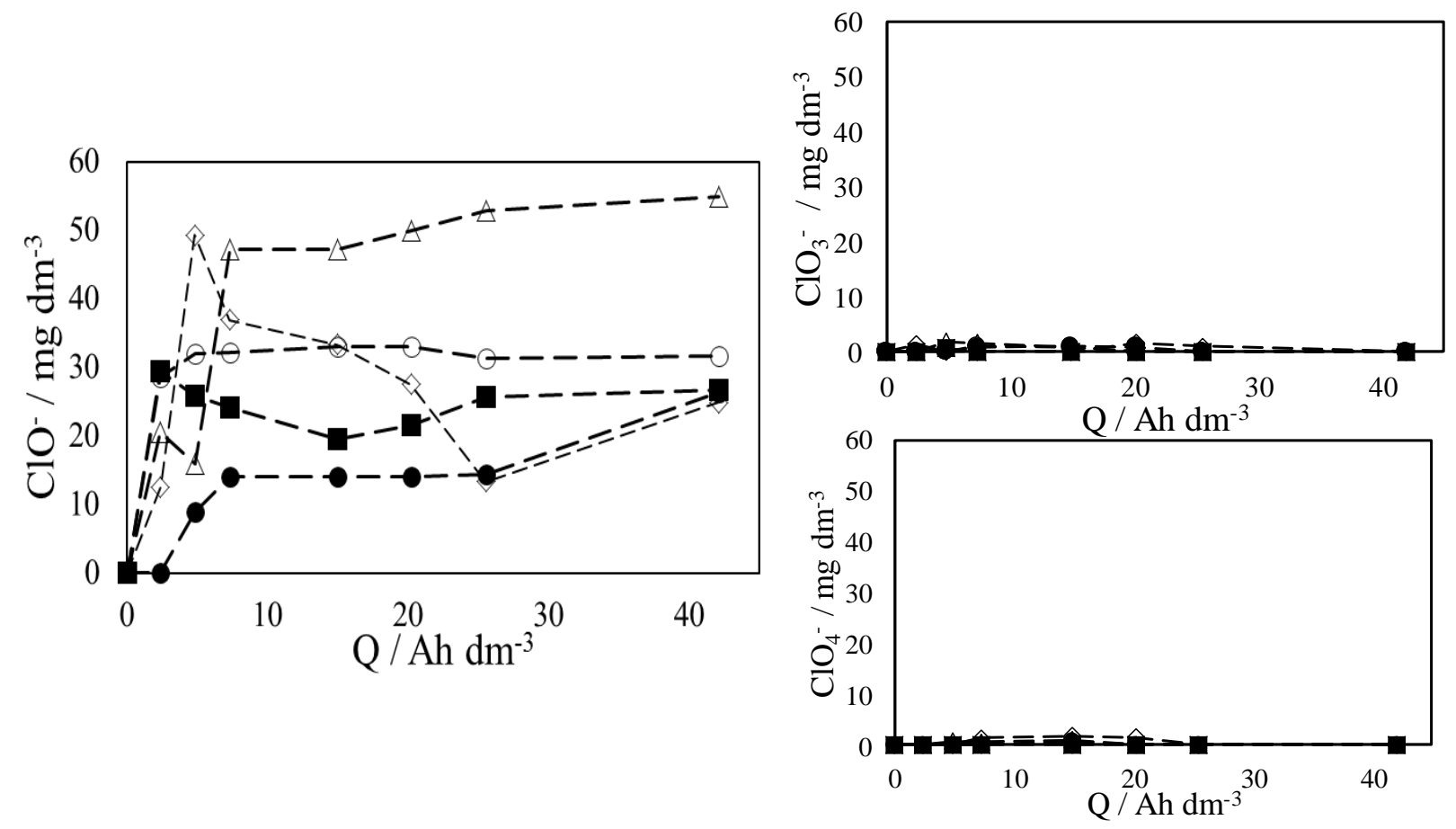
Fig. 8. $\mathrm{ClO}^{-}, \mathrm{ClO}_{3}{ }^{-}$and $\mathrm{ClO}_{4}{ }^{-}$produced during the electrolytic treatment $\left(\mathrm{j}=300 \mathrm{~A} \mathrm{~m}^{-2}\right)$ of $\mathrm{SASW}$ effluents obtained during the soil washing with different SDS/soil dosages: $(\diamond) 0.5 \mathrm{~g} \mathrm{~kg}^{-1},(\Delta) 2.5 \mathrm{~g}$ $\mathrm{kg}^{-1},(\bullet) 5.0 \mathrm{~g} \mathrm{~kg}^{-1},(\circ) 12.5 \mathrm{~g} \mathrm{~kg}^{-1}$ and (๘) $25.0 \mathrm{~g} \mathrm{~kg}^{-1}$.

Very recently the role of some species such as hydrogen peroxide in preventing the formation of perchlorates has been pointed out $[45,46]$. This hydrogen peroxide can be produced from the decomposition of persulfate, so occurrence of persulfates at higher concentration can be preventing the oxidation of chloride to perchlorate and chlorate. Anyhow, at the light of the present knowledge we can only hypothesized this fact and more work has to be done in order to confirm this behavior.

\section{Conclusions}

From this work, the following conclusions can be drawn:

- Surfactant aided soil washing with SDS solutions is an efficient technology from the removal of oxyfluorfen from spiked soils. With dosages below $5.0 \mathrm{~g} \mathrm{Kg}^{-1}$ soil total depletion of the pesticide is attained.

- Characteristics of the effluents obtained in the SASW process depend largely on the SDS/soil dosage. In spite of having the same chemical compounds, effluents are and behave in a completely different way, in particular because of the very different type of microdrops.

- Electrolysis with diamond is an efficient technology for the removal of SAWS effluents obtained in soils polluted with oxyfluorfen. Total mineralization is attained during the process and oxidation of pesticide, SDS and decrease in size of drops occurs simultaneously.

- Rate of removal of SDS is faster than that of oxyfluorfen. During the electrolysis, sulphate coming from the SDS molecules are release to the solution favouring the enhancement in the 
process efficiency by mediated electrolysis. Chlorine coming from oxyfluorfen is also released and it is mainly transformed into hypochlorite.

- Opposite to other advanced oxidation processes, production of intermediates is almost negligible in this process. Only 4-(trifluoromethyl)-phenol and ortho-nitrophenol were detected by HPLC as the main byproducts from the oxidation of oxyfluorfen. No intermediates coming from SDS were detected in spite of the high concentrations of SDS in several of the effluents. This indicates that intermediates formed during the process are very rapidly oxidized and that most important processes occur on the micelles surfaces.

\section{Acknowledgements}

The authors acknowledge funding support from the EU and Spanish Government through the MINECO Project CTM2013-45612-R, FEDER 2007-2013 PP201010 (Planta Piloto de Estación de Estación de Regeneración de Aguas Depuradas) and INNOCAMPUS. Brazil government by grant for PhD fellowship scholarship given for "doutorado sanduiche" under "Ciências sem Fronteiras" program to develop the experimental research at the UCLM-Spain is gratefully acknowledged.

\section{References}

[1] N. Mantzos, A. Karakitsou, D. Hela, G. Patakioutas, E. Leneti, I. Konstantinou, Persistence of oxyfluorfen in soil, runoff water, sediment and plants of a sunflower cultivation, Science of the Total Environment, 472 (2014) 767-777.

[2] C.A. Alister, P.A. Gomez, S. Rojas, M. Kogan, Pendimethalin and oxyfluorfen degradation under two irrigation conditions over four years application, Journal of Environmental Science and Health Part B-Pesticides Food Contaminants and Agricultural Wastes, 44 (2009) 337-343.

[3] A.C. Das, A. Debnath, D. Mukherjee, Effect of the herbicides oxadiazon and oxyfluorfen on phosphates solubilizing microorganisms and their persistence in rice fields, Chemosphere, 53 (2003) 217-221.

[4] S. Sondhia, A. Dixit, Persistence of oxyfluorfen residues in the soil of paddy field and detection of its residues in crop produce, Indian Journal of Agricultural Sciences, 80 (2010) 926-929.

[5] A.T. Hall, B.D. McGaughey, J.A. Gagne, Data Quality, Reliability, and Relevance Stand ards for Ecological Risk Assessment: Recommendations for Improvements to Pesticide Regulation in Compliance with the Endangered Species Act, Pesticide Regulation and the Endangered Species Act, 1111 (2012) 225-242. 
[6] E.V.D. Santos, C. Sáez, C.A. Martínez-Huitle, P. Cañizares, M.A. Rodrigo, The role of particle size on the conductive diamond electrochemical oxidation of soil-washing effluent polluted with atrazine, Electrochemistry Communications, 55 (2015) 26-29.

[7] R. Lopez-Vizcaino, C. Saez, P. Canizares, M.A. Rodrigo, The use of a combined process of surfactant-aided soil washing and coagulation for PAH-contaminated soils treatment, Separation and Purification Technology, 88 (2012) 46-51.

[8] C. Saez, R. Lopez-Vizcaino, P. Canizares, M.A. Rodrigo, Conductive-Diamond Electrochemical Oxidation of Surfactant-Aided Soil-Washing Effluents, Industrial \& Engineering Chemistry Research, 49 (2010) 9631-9635.

[9] M.A. Rodrigo, N. Oturan, M.A. Oturan, Electrochemically Assisted Remediation of Pesticides in Soils and Water: A Review, Chemical Reviews, 114 (2014) 8720-8745.

[10] E.V. dos Santos, S.F.M. Sena, D.R. da Silva, S. Ferro, A. De Battisti, C.A. Martínez-Huitle, Scale-up of electrochemical oxidation system for treatment of produced water generated by Brazilian petrochemical industry, Environmental Science and Pollution Research, (2014).

[11] M. Panizza, I. Sires, G. Cerisola, Anodic oxidation of mecoprop herbicide at lead dioxide, Journal of Applied Electrochemistry, 38 (2008) 923-929.

[12] I. Sires, E. Brillas, G. Cerisola, M. Panizza, Comparative depollution of mecoprop aqueous solutions by electrochemical incineration using $\mathrm{BDD}$ and $\mathrm{PbO} 2$ as high oxidation power anodes, Journal of Electroanalytical Chemistry, 613 (2008) 151-159.

[13] A.M. Polcaro, M. Mascia, S. Palmas, A. Vacca, Electrochemical degradation of diuron and dichloroaniline at BDD electrode, Electrochimica Acta, 49 (2004) 649-656.

[14] A.M. Polcaro, A. Vacca, M. Mascia, S. Palmas, Oxidation at boron doped diamond electrodes: an effective method to mineralise triazines, Electrochimica Acta, 50 (2005) 1841-1847.

[15] L. Martinez Nieto, G. Hodaifa, M.S. Casanova, Elimination of pesticide residues from virgin olive oil by ultraviolet light: Preliminary results, Journal of Hazardous Materials, 168 (2009) 555559.

[16] F. Fdil, J.J. Aaron, N. Oturan, A. Chaouch, M.A. Oturan, Dégradation photochimique d'herbicides chlorophenoxyalcanoïques en milieux aqueux, Rev Sci Eau, 16 (2003) 123.

[17] M. Diagne, N. Oturan, M.A. Oturan, I. Sires, UV-C light-enhanced photo-Fenton oxidation of methyl parathion, Environmental Chemistry Letters, 7 (2009) 261-265.

[18] N. Oturan, E. Brillas, M.A. Oturan, Unprecedented total mineralization of atrazine and cyanuric acid by anodic oxidation and electro-Fenton with a boron-doped diamond anode, Environmental Chemistry Letters, 10 (2012) 165-170.

[19] G. Kaichouh, N. Oturan, M.A. Oturan, A. El Hourch, K. El Kacemi, Mineralization of herbicides imazapyr and imazaquin in aqueous medium by, Fenton, photo-Fenton and electroFenton processes, Environmental Technology, 29 (2008) 489-496.

[20] B. Balci, M.A. Oturan, N. Oturan, I. Sires, Decontamination of Aqueous Glyphosate, (Aminomethyl) phosphonic Acid, and Glufosinate Solutions by Electro-Fenton-like Process with Mn2+ as the Catalyst, Journal of Agricultural and Food Chemistry, 57 (2009) 4888-4894.

[21] I. Sirés, E. Brillas, M.A. Oturan, M.A. Rodrigo, M. Panizza, Electrochemical advanced oxidation processes: today and tomorrow. A review, Environmental Science and Pollution Research, (2014).

[22] H.T. Madsen, E.G. Sogaard, J. Muff, Study of degradation intermediates formed during electrochemical oxidation of pesticide residue 2,6-dichlorobenzamide (BAM) in chloride medium at boron doped diamond (BDD) and platinum anodes, Chemosphere, 120 (2015) 756-763.

[23] G.R.P. Malpass, D.W. Miwa, S.A.S. Machado, P. Olivi, A.J. Motheo, Oxidation of the pesticide atrazine at DSA (R) electrodes, Journal of Hazardous Materials, 137 (2006) 565-572.

[24] M. Panizza, M. Delucchi, G. Cerisola, Electrochemical degradation of anionic surfactants, Journal of Applied Electrochemistry, 35 (2005) 357-361. 
[25] E. Weiss, K. Groenen-Serrano, A. Savall, Electrochemical mineralization of sodium dodecylbenzenesulfonate at boron doped diamond anodes, Journal of Applied Electrochemistry, 37 (2007) 1337-1344.

[26] B. Louhichi, M.F. Ahmadi, N. Bensalah, A. Gadri, M.A. Rodrigo, Electrochemical degradation of an anionic surfactant on boron-doped diamond anodes, Journal of Hazardous Materials, 158 (2008) 430-437.

[27] B. Marselli, J. Garcia-Gomez, P.A. Michaud, M.A. Rodrigo, C. Comninellis, Electrogeneration of hydroxyl radicals on boron-doped diamond electrodes, Journal of the Electrochemical Society, 150 (2003) D79-D83.

[28] D.M.D. Araújo, C. Sáez, C.A. Martínez-Huitle, P. Cañizares, M.A. Rodrigo, Influence of mediated processes on the removal of Rhodamine with conductive-diamond electrochemical oxidation, Applied Catalysis B: Environmental, 166-167 (2015) 454-459.

[29] S. Velazquez-Pena, C. Saez, P. Canizares, I. Linares-Hernandez, V. Martinez-Miranda, C. Barrera-Diaz, M.A. Rodrigo, Production of oxidants via electrolysis of carbonate solutions with conductive-diamond anodes, Chemical Engineering Journal, 230 (2013) 272-278.

[30] M.A. García-Morales, G. Roa-Morales, C. Barrera-Díaz, B. Bilyeu, M.A. Rodrigo, Synergy of electrochemical oxidation using boron-doped diamond (BDD) electrodes and ozone (O3) in industrial wastewater treatment, Electrochemistry Communications, 27 (2013) 34-37.

[31] I. Sires, E. Brillas, M.A. Oturan, M.A. Rodrigo, M. Panizza, Electrochemical advanced oxidation processes: today and tomorrow. A review, Environmental Science and Pollution Research, 21 (2014) 8336-8367.

[32] E. Brillas, C.A. Martínez-Huitle, Decontamination of wastewaters containing synthetic organic dyes by electrochemical methods. An updated review, Applied Catalysis B: Environmental, 166167 (2015) 603-643.

[33] M.A. Rodrigo, P. Canizares, A. Sanchez-Carretero, C. Saez, Use of conductive-diamond electrochemical oxidation for wastewater treatment, Catalysis Today, 151 (2010) 173-177.

[34] P. Canizares, C. Saez, A. Sanchez-Carretero, M.A. Rodrigo, Synthesis of novel oxidants by electrochemical technology, Journal of Applied Electrochemistry, 39 (2009) 2143-2149.

[35] E. Jurado, M. Fernandez-Serrano, J. Nunez-Olea, G. Luzon, M. Lechuga, Simplified spectrophotometric method using methylene blue for determining anionic surfactants: Applications to the study of primary biodegradation in aerobic screening tests, Chemosphere, 65 (2006) 278-285.

[36] F.L. Souza, C. Saez, P. Canizares, A.J. Motheo, M.A. Rodrigo, Coupling photo and sono technologies to improve efficiencies in conductive diamond electrochemical oxidation, Applied Catalysis B-Environmental, 144 (2014) 121-128.

[37] R. Lopez-Vizcaino, C. Saez, P. Canizares, V. Navarro, M.A. Rodrigo, Influence of the Type of Surfactant on the Mobility of Flushing Fluids for Electro-Remediation Processes, Separation Science and Technology, 46 (2011) 2148-2156.

[38] R. Lopez-Vizcaino, C. Saez, P. Canizares, M.A. Rodrigo, Electrocoagulation of the effluents from surfactant-aided soil-remediation processes, Separation and Purification Technology, 98 (2012) 88-93.

[39] M. Panizza, A. Barbucci, M. Delucchi, M.P. Carpanese, A. Giuliano, M. Cataldo-Hernandez, G. Cerisola, Electro-Fenton degradation of anionic surfactants, Separation and Purification Technology, 118 (2013) 394-398.

[40] K. Serrano, P.A. Michaud, C. Comninellis, A. Savall, Electrochemical preparation of peroxodisulfuric acid using boron doped diamond thin film electrodes, Electrochimica Acta, 48 (2002) 431-436.

[41] H. Bergmann, A.T. Koparal, A.S. Koparal, F. Ehrig, The influence of products and by-products obtained by drinking water electrolysis on microorganisms, Microchemical Journal, 89 (2008) 98107. 
[42] M.E.H. Bergmann, A.S. Koparal, T. Iourtchouk, Electrochemical Advanced Oxidation Processes, Formation of Halogenate and Perhalogenate Species: A Critical Review, Critical Reviews in Environmental Science and Technology, 44 (2014) 348-390.

[43] A. Cano, P. Canizares, C. Barrera, C. Saez, M.A. Rodrigo, Use of low current densities in electrolyses with conductive-diamond electrochemical - Oxidation to disinfect treated wastewaters for reuse, Electrochemistry Communications, 13 (2011) 1268-1270.

[44] A. Cano, P. Canizares, C. Barrera-Diaz, C. Saez, M.A. Rodrigo, Use of conductive-diamond electrochemical-oxidation for the disinfection of several actual treated wastewaters, Chemical Engineering Journal, 211 (2012) 463-469.

[45] S. Cotillas, J. Llanos, M.A. Rodrigo, P. Canizares, Use of carbon felt cathodes for the electrochemical reclamation of urban treated wastewaters, Applied Catalysis B-Environmental, 162 (2015) 252-259.

[46] J. Llanos, S. Cotillas, P. Canizares, M.A. Rodrigo, Conductive diamond sono-electrochemical disinfection (CDSED) for municipal wastewater reclamation, Ultrasonics Sonochemistry, 22 (2015) 493-498. 